\title{
Heart Rate Variability in Patients of Recurrent Stroke as Compared to Patients of First-Ever Stroke
}

\author{
Swati Mishra ${ }^{1}$, Supriya Gupta ${ }^{2}$, Raj Kapoor ${ }^{3}$, Bhavna Kaul ${ }^{4}$ \\ ${ }^{1}$ Senior Resident, Dept of Physiology, Shaheed Hasan Khan Mewati Govt Medical College, Nuh, Haryana \\ ${ }^{2}$ Director Professor, Dept of Physiology, Vardhman Mahavir Medical College and Safdarjung Hospital, \\ New Delhi \\ ${ }^{3}$ Director Professor (Physiology), Vardhman Mahavir Medical College and Safdarjung Hospital, New Delhi \\ ${ }^{4}$ Associate Professor, Dept of Neurology, Vardhman Mahavir Medical College and Safdarjung Hospital, \\ New Delhi \\ Corresponding Author: Swati Mishra
}

DOI: https://doi.org/10.52403/ijhsr.20220201

\begin{abstract}
Background- Cardiac autonomic neuropathy (CAN) is a common complication in stroke patients; both in acute and chronic phase. Multiple studies have found impaired cardiovagal or parasympathetic function in stroke patients which may result in cardiac arrhythmias and sudden death. Autonomic dysfunction increases cardiovascular risk in patients of first-ever stroke, but to the best of our knowledge very few studies have investigated if this risk is further increased in patients of recurrent stroke.

Aim- To assess and compare, the cardiovascular autonomic functions via heart rate variability (HRV), and therefore, the cardiovascular risk, in patients of recurrent stroke and patients of first - ever stroke. Methods- 30 recurrent stroke patients and 30 first - ever stroke patients were recruited for this study. Heart Rate Variability (HRV) was used to assess cardiovascular autonomic function.

Results - Time domain parameters- SDNN ( $\mathrm{p}=0.011)$, rMSSD ( $=0.031)$ and $\mathrm{pNN} 50(\mathrm{p}=0.041)$ and frequency domain parameters - LF power $(p=0.011)$, HF power $(p=0.026)$, TP $(p=0.022)$ were significantly reduced in recurrent stroke patients as compared to with a single stroke event

Conclusion- Our preliminary study shows that parasympathetic function is significantly reduced in patients with recurrent stroke than in patients with a single stroke event. This may indicate an increased risk of adverse cardiovascular events and cardiac mortality in patients of recurrent stroke.
\end{abstract}

Key Words - Cardiac Autonomic neuropathy, HRV, Stroke, recurrent stroke

Key Message - Patients of stroke and recurrent stroke must undergo assessment of cardiac autonomic functions.

\section{INTRODUCTION}

Stroke is one of the leading causes of death and disability globally. ${ }^{1}$ In India, the estimated prevalence ranges from 84$262 / 100,000$ in rural to $334-424 / 100,000$ in urban areas and the incidence rate is 119$145 / 100,000$ based on the recent population based studies. ${ }^{2}$ Stroke is defined according to the World Health Organization criteria as "rapidly developing symptoms and/or signs of focal, and at times global, loss of cerebral function, with symptoms lasting more than 24 hours or leading to death with no apparent cause other than that of vascular origin." 3 The autonomic nervous system (ANS) is responsible for fast, continuous and normally subconscious control of basic physiological functions like heart rate, blood pressure, etc. ${ }^{4}$ It has two major divisions sympathetic and parasympathetic. 

stroke.

Heart Rate Variability (HRV) is the oscillation in the interval between consecutive heart beats as well as the oscillations between consecutive instantaneous heart rate. $^{5}$ Heart Rate Variability (HRV) is a physiological phenomenon which reflects the influence of the autonomic nervous system on the heart. ${ }^{6}$ Reduced heart rate variability predicted increased risk for subsequent cardiac events in Framingham heart study. ${ }^{7} \mathrm{HRV}^{5}$ is analysed in two domains- Time Domain analysis consists of Standard Deviation of all N-N intervals (SDNN), square root of the mean squared differences of successive NN intervals (RMSSD), percentage of adjacent NN differing by more than $50 \mathrm{~ms}$ (pNN50) and Mean Heart Rate. Frequency Domain analyses consists of Total Power (TP) which reflects overall autonomic activity where sympathetic activity is a primary contributor, Low Frequency (LF) which is a strong indicator of sympathetic activity, High Frequency (HF) which reflects parasympathetic (vagal) activity, Very Low Frequency (VLF) which is a band of power spectrum range between 0.003 and $0.04 \mathrm{~Hz}$ and $\mathrm{LF} / \mathrm{HF}$ ratio which indicates overall balance between sympathetic and parasympathetic nervous systems.

The risk of a recurrent stroke occurring in the first year following index stroke is 8.5 times greater than the risk of first stroke in the general population. ${ }^{8}$ Among stroke patients cardiovascular mortality is high. ${ }^{9}$ Hankey et al ${ }^{9}$ in PCSS found that most common cause of death after one year of index stroke was recurrent stroke and cardiovascular causes.

$85 \%$ stroke cases are of ischemic subtype and ischemic strokes are associated with cardiac autonomic dysfunction [10-15] and reduced HRV 6,10,16,17,18,19 This may be due to damage to central autonomic network or autonomic pathways descending from hypothalamus to the spinal cord ${ }^{12}$. Ischemic stroke patients show a parasympathetic cardiac deficit ${ }^{10,20}$ which may manifest as increased heart rate or blood pressure changes. Stroke patients have high rates of cardiac arrhythmia in the acute post-stroke phase $^{21}$ and decreased vagal tone is believed to be correlated with paroxysmal atrial fibrillation $^{22,23}$. These are risk factors for stroke and may contribute to a recurrent stroke or increased cardiac mortality in stroke patients. Cardiac arrhythmias and recurrent stroke are common complications in stroke patients. ${ }^{24}$ Reduced heart rate variability has been consistently associated with increased risk of cardiac and overall mortality, and it is hypothesized that this is because of sudden arrhythmic death caused by autonomic imbalance ${ }^{25}$. Heart rate variability has an impact on hypertension, atherosclerosis and cardiovascular mortality ${ }^{17}$. Many studies have assessed autonomic functions in stroke patients with HRV ${ }^{6,10,16,17,18,19 ~ a n d ~ h a v e ~ f o u n d ~ t h a t ~ H R V ~}$ is reduced in patients of stroke and stays significantly low even after months of stroke event $10,11,12$ and overall stroke patients have parasympathetic deficit.

Till date, to the best of our knowledge, hardly any studies have been conducted to assess whether autonomic dysfunction is further deranged after a recurrent stroke, thereby increasing the risk of sudden cardiac death and reducing favourable prognosis in such patients. Our study was designed to assess if there is any further derangement of autonomic dysfunction in patients of recurrent stroke, whether the autonomic dysfunction shows the same pattern of parasympathetic deficit and whether severity of autonomic dysfunction is increased in recurrent stroke patients.

\section{MATERIALS AND METHODS}

The present study was conducted in the Department of Physiology and was commenced after obtaining clearance from the institutional Ethical Committee. Sixty ischemic stroke patients, age 25 years to 75 years, were recruited for this study. They were divided into two groups - thirty patients of first-time stroke and thirty of recurrent (> one) stroke. 

stroke.

Recurrent stroke was defined as a new cerebrovascular event that met one of the following criteria: the event resulted in a neurological deficit that was clearly different from that of the index stroke; the event involved a different anatomic site or vascular territory from that of the index stroke. ${ }^{26}$ Patients with haemorrhagic stroke, large lesions (>1/3rd of Middle Cerebral Artery or $>1 / 3$ rd of Posterior cerebral artery territory), history of previous Cardiac disease like Myocardial Infarction or Angina and uncontrolled Diabetes Mellitus were excluded from the study. The cases were referred from Neurology OPD and selected on basis of MRI report of the subject. In case of recurrent stroke, both previous and current MRI reports were required.

The subjects were explained about the procedure and informed consent was taken. Subjects were instructed to refrain from caffeine/tea ingestion from one day prior to the day of investigations and to come after having a light breakfast 2 hours prior to testing. The temperature of the AFT lab was maintained between $23^{\circ} \mathrm{C}$ to $25^{\circ} \mathrm{C}$. The subjects were allowed to rest in supine position for ten minutes and get used to experimental and environmental conditions in the lab.

The ECG was recorded using BIOPAC MP 150 Data Acquisition System (BIOPAC systems Inc., Goleta, CA) in well controlled condition in a semi-darkened and silent room. A five-minute ECG record was taken in supine position with the patient breathing naturally and HRV analysis was done with Kubios HRV Pro Version software (Kuopio, Finland) and time domain and frequency domain parameters were obtained.

Statistical analysis - distribution of sex, hypertension and history of diabetes were differentiated through chi-square test. Difference of mean age was tested by independent t-test. Normally distributed continuous variables were compared using the unpaired $\mathrm{t}$ test, whereas the Mann-
Whitney U test was used for those variables that were not normally distributed. Statistical analysis was performed by the SPSS program for windows, version 17.0 (SPSS, Chicago, Illinois). For all statistical tests, a p-value less than 0.05 was taken to indicate a significant difference.

\section{RESULTS}

The demographic profile of patients in the two groups of our study, i.e., the firsttime stroke group and recurrent stroke group, were similar with respect to age, sex and BMI (Table 1). The frequency of patients with hypertension and diabetes mellitus type II was similar in both groups (Table 1).

Among the baseline parameters (Table 2) Systolic BP and Heart Rate were similar but significant difference is seen in Diastolic BP with a higher value in recurrent stroke group.

HRV parameters (Table 3) show that in the recurrent stroke group the following time domain parameters were significantly reduced- SDNN $\quad(\mathrm{p}=0.011), \quad \mathrm{rMSSD}$ $(\mathrm{p}=0.031)$ and $\mathrm{pNN} 50 \quad(\mathrm{p}=0.041) \quad$ as compared to single stroke group. Mean heart rate was also higher in recurrent stroke group but increase was not significant $(\mathrm{p}=0.05)$. In the recurrent stroke group, the following frequency domain parameters were significantly reduced $-\mathrm{LF}$ power $(\mathrm{p}=0.011), \quad \mathrm{HF}$ power $\quad(\mathrm{p}=0.026), \quad \mathrm{TP}$ $(\mathrm{p}=0.022)$ as compared to single stroke group. $\mathrm{LF} / \mathrm{HF}$ ratio was also higher in recurrent stroke group but the increase was not significant.

Table 1- Demographic profile of the patients
\begin{tabular}{|l|l|l|l|}
\hline Characteristics & $\begin{array}{l}\text { First-time } \\
\text { stroke } \\
\text { n=30 }\end{array}$ & $\begin{array}{l}\text { Recurrent } \\
\text { stroke } \\
\text { n=30 }\end{array}$ & $\begin{array}{l}\text { p } \\
\text { value }\end{array}$ \\
\hline $\begin{array}{l}\text { Mean age (years) } \\
\text { mean } \pm \text { SD) }\end{array}$ & $49.53 \pm 14.06$ & $55.50 \pm 13.32$ & 0.097 \\
\hline $\begin{array}{l}\text { BMI } \\
\text { (mean } \pm \text { SD) }\end{array}$ & $23.29 \pm 3.80$ & $24.65 \pm 4.20$ & 0.193 \\
\hline Male (n\%) & $26(86.7 \%)$ & $23(76.7 \%)$ & 0.506 \\
\hline $\begin{array}{l}\text { Hypertension } \\
\text { (n\%) }\end{array}$ & $17(56.7 \%)$ & $21(70 \%)$ & 0.284 \\
\hline DM type II (n\%) & $6(20 \%)$ & $3(10 \%)$ & 0.472 \\
\hline
\end{tabular}


Swati Mishra et.al. Heart rate variability in patients of recurrent stroke as compared to patients of first-ever stroke.

Table 2 - Comparison of Baseline cardiovascular parameters between First-time and recurrent stroke group

\begin{tabular}{|l|l|l|l|}
\hline $\begin{array}{l}\text { Basal } \\
\text { cardiovascular } \\
\text { parameter }\end{array}$ & $\begin{array}{l}\text { First-time } \\
\text { stroke }(\mathbf{n = 3 0})\end{array}$ & $\begin{array}{l}\text { Recurrent } \\
\text { stroke }(\mathbf{n}=\mathbf{3 0})\end{array}$ & $\begin{array}{l}\mathbf{p} \\
\text { Value }\end{array}$ \\
\hline $\mathrm{SBP}(\mathrm{mm} \mathrm{Hg})$ & $128.43 \pm 19.87$ & $133.53 \pm 18.39$ & 0.307 \\
\hline $\mathrm{DBP}(\mathrm{mm} \mathrm{Hg})$ & $79.60 \pm 11.55$ & $86.10 \pm 12.80$ & $0.043^{*}$ \\
\hline $\begin{array}{l}\mathrm{HR} \text { (beats per } \\
\text { minute) }\end{array}$ & $70.83 \pm 12.00$ & $76.37 \pm 11.66$ & 0.075 \\
\hline
\end{tabular}

All values are presented as mean $\pm S D$. Abbreviations - SBP Systolic blood pressure, DBP - Diastolic Blood pressure, HR Heart Rate. * p value $<0.05$

Table 3 - Comparison of Heart Rate Variability parameters between First-time and recurrent stroke group

\begin{tabular}{|l|l|l|l|}
\hline HRV Parameters & $\begin{array}{l}\text { First-time } \\
\text { stroke } \\
\mathbf{n = 3 0}\end{array}$ & $\begin{array}{l}\text { Recurrent } \\
\text { stroke } \\
\mathbf{n = 3 0}\end{array}$ & $\begin{array}{l}\mathbf{p} \\
\text { value }\end{array}$ \\
\hline SDNN (ms) & $35.71 \pm 17.73$ & $25.63 \pm 11.23$ & $0.011^{*}$ \\
\hline rMSSD (ms) & $35.16 \pm 26.45$ & $22.11 \pm 16.43$ & $0.031^{*}$ \\
\hline pNN50 (\%) & $7.78 \pm 12.76$ & $4 \pm 8.51$ & $0.041^{*}$ \\
\hline $\begin{array}{l}\text { Mean HR } \\
\text { per minute) }\end{array}$ & $71.52 \pm 11.88$ & $77.3 \pm 12.54$ & 0.05 \\
\hline LF - Power $\left(\mathrm{ms}^{2}\right)$ & $466.3 \pm 626.2$ & $136.7 \pm 166.6$ & $0.011^{*}$ \\
\hline HF - Power $\left(\mathrm{ms}^{2}\right)$ & $545 \pm 844.9$ & $214.6 \pm 366.9$ & $0.026^{*}$ \\
\hline $\begin{array}{l}\text { Total power (TP) } \\
\left.(\mathrm{ms})^{2}\right)\end{array}$ & $1497 \pm 1733$ & $641.2 \pm 625.5$ & $0.022^{*}$ \\
\hline LF/HF ratio & $1.41 \pm 1.35$ & $1.89 \pm 2.08$ & 0.944 \\
\hline
\end{tabular}

All values are presented as mean $\pm S D$. *p value <0.05. SDNN Standard Deviation of all N-N intervals, RMSSD- square root of the mean squared differences of successive NN intervals, pNN50percentage of adjacent $N N$ differing by more than 50ms, HR Heart Rate, LF-Low Frequency, HF-High Frequency.

\section{DISCUSSION}

\section{Time domain parameters of $\mathrm{HRV}$}

SDNN - Both sympathetic and parasympathetic activity contribute to SDNN and it is considered to be gold standard for medical stratification of cardiac risk when recorded over 24 hours. ${ }^{5}$ SDNN was significantly reduced in recurrent stroke group $(p$ value $=0.011)$. Low SDNN may indicate increased cardiovascular risk in these patients.

Many studies ${ }^{6,18,27,30}$ have found that SDNN is significantly reduced in stroke patients. Reduced SDNN was found to be correlated with increased sudden mortality $^{18}$, associated with frequent and complex arrhythmias in patients of stroke ${ }^{28}$, and an independent predictor of unfavorable functional outcome in patients of ischemic stroke $^{29}$. Binici et $\mathrm{al}^{17}$ found that reduced SDNN and reduced nighttime HRV were associated with increased stroke risk. Reduced SDNN reflects a reduced vagal activity directed to the heart which may cause increased sympathetic modulation of heart and cardiac electrical instability.
rMSSD and pNN50, which represent parasympathetic activity, were also significantly reduced in recurrent stroke group as compared to single stroke group (p value for $\mathrm{rMSSD}=0.031)(\mathrm{p}$ value and pNN50 = 0.041). The reduced values of rMSSD and pNN50 indicate parasympathetic dysfunction and decreased parasympathetic activity. Mean heart rate (mean HR) was higher in recurrent stroke group which might be due to parasympathetic deficit.

Multiple studies 10,11,13,14,16 have already established that stroke patients have a parasympathetic deficit as compared to healthy subjects. Orlandi et $\mathrm{al}^{31}$ found that pNN50 was significantly reduced in hyperacute stroke patients with arrhythmia.

In our study we observed that patients of recurrent stroke have a more pronounced parasympathetic deficit, as seen by significantly low rMSSD and pNN50. A reduced SDNN may indicate an increased risk of cardiac mortality in patients who have had a stroke recurrence.

Increased mean Heart Rate in patients of recurrent stroke (77 bpm) may indicate a poor prognosis and increased cardiovascular risk. In PROFESS ${ }^{32}$ (The Prevention Regimen for Effectively Avoiding Second Stroke) it was observed that stroke patients with baseline heart rate $\geq 76 \mathrm{bpm}$ had a higher risk of total death, vascular death, and non-vascular death. They also found significant association between heart rate and functional neurological outcomes after a recurrent stroke. Reduction in heart rate may be a potential therapeutic target in stroke patients.

\section{Frequency domain parameters of $\mathrm{HRV}$}

LF, a measure of sympathetic activity, was significantly reduced in recurrent stroke group $(p=0.011)$. HF, a measure of parasympathetic activity, was also significantly reduced in patients of recurrent stroke $(\mathrm{p}=0.026)$. Total power $\mathrm{TP}$ was also significantly reduced in recurrent stroke group $(\mathrm{p}=0.022)$. 

stroke.

Multiple studies have found that stroke patients had significantly reduced $\mathrm{LF}^{10,16,18}, \mathrm{HF}^{10,14,16,18,30}, \mathrm{VLF}^{16}$ and $\mathrm{TP}^{6,10}$, and an increased LF/HF ratio ${ }^{14,16,18}$. LF and $\mathrm{HF}$ were reduced in patients of ischemic stroke in acute phase and after 6 months of stroke event ${ }^{12}$, and have been found to be correlated with sudden mortality ${ }^{18}$.

While most studies have focused on HRV patterns of stroke patients as compared to normal healthy subjects, we have assessed the effect of a recurrent stroke on HRV.

Recurrent stroke is one of the common complications of stroke and fatality rate is quite high in case of a recurrent stroke as compared to first ever stroke. ${ }^{8}$ Significantly reduced HRV parameters, especially those which indicate parasympathetic function like rMSSD, pNN50 and HF, show that patients of recurrent stroke have an even more profound parasympathetic deficit than patients with a single stroke event. This leads to a relatively increased sympathetic activity, which may cause - cardiac arrhythmias and increased basal blood pressure. Both these increase stress on heart, damage vessel endothelium and promote plaque formation. Atrial fibrillation, changes in blood pressure, and thrombus formation- independently and togetherincrease risk of future adverse cardiovascular and cerebrovascular events. A significantly reduced parasympathetic activity after a second stroke may lead to unfavorable outcome, and autonomic status in such patients must be assessed.

Further research is required on the impact of autonomic status testing on prognosis and functional outcome of stroke patients. Whether or not autonomic dysfunction is an independent risk factor for sudden cardiac mortality in patients of cerebrovascular accidents also remains to be studied. Research into the pattern and severity of autonomic dysfunction in correlation with specific cortical areas may also shed some light on the cortical control and regulation of the central autonomic network.

Limitations - In this study we did not categorise patients on basis of cortical areas involved in stroke. We also did not differentiate between patients of ipsilateral recurrent stroke and contralateral recurrent stroke (compared to side of first stroke event).

\section{CONCLUSION}

In our preliminary study we found that patients of recurrent stroke have a reduced HRV as compared to patients of single stroke event. Recurrent stroke patients also have a more severe parasympathetic dysfunction as compared to patients with single stroke event.

\section{Acknowledgement: None}

Conflict of Interest: None

\section{Source of Funding: None}

\section{Ethical Approval: Approved}

\section{REFERENCES}

1. Mozaffarian D, Benjamin EJ, Go AS, Arnett DK, Blaha MJ, Cushman M et al. Heart Disease and Stroke Statistics-2016 Update. Circulation. 2015; 133:e38-e360.

2. Pandian J, Sudhan P. Stroke Epidemiology and Stroke Care Services in India. Journal of Stroke. 2013;15(3):128-134.

3. Hatano S. Experience from a multicentre stroke register: a preliminary report. Bull World Health Organ. 1980; 58:113-130.

4. Günther A. Autonomic Dysfunction and Risk Stratification Assessed from Heart Rate Pattern. The Open Neurology Journal. 2010; 4(1):39-49.

5. Heart rate variability. Standards of measurement, physiological interpretation, and clinical use. Task Force of The European Society of Cardiology and The North America Society of Pacing and Electrophysiology. European Heart Journal. 1996; 17: 354-381.

6. Lakusić N, Mahović D, Babić T, Sporis D. Changes in autonomic control of heart rate 
after ischemic cerebral stroke. Acta Med Croatica 2003; 57(4): 269-73.

7. Tsuji H, Larson MG, Venditti FJ, Jr, Manders ES, Evans JC, Feldman CL, Levy D. Impact of reduced heart rate variability on risk for cardiac events. The Framingham Heart Study. Circulation. 1996;94:28502855.

8. Hankey GJ, Jamrozik K, Broadhurst RJ, Forbes S, Burvill PW, Anderson CS et al. Long term risk of first recurrent stroke in the Perth community stroke study. Stroke.1998; 29; 2491-2500.

9. Hankey G, Jamrozik K, Broadhurst R, Forbes S, Burvill P, Anderson C et al. FiveYear Survival After First-Ever Stroke and Related Prognostic Factors in the Perth Community Stroke Study. Stroke. 2000; 31:2080-2086.

10. McLaren A, Kerr S, Allan L, Steen N, Ballard C, Allen J et al. Autonomic function is impaired in elderly stroke survivors. Stroke.2005; 36:1026-1030.

11. Xiong L, Leung HH, Chen XY, Han JH, Leung TW, Soo YO et al. Comprehensive assessment for autonomic dysfunction in different phases after ischaemic stroke. Int $\mathbf{J}$ Stroke. 2013; 8(8):645-651.

12. Korpelainen JT, Sotaniemi KA, Myllylä VV - Autonomic nervous system disorders in stroke. Clin Auton Res. 1999 Dec; 9(6):32533.

13. Korpelainen JT, Sotaniemi AK, Suominen K, Tolonen U, Myllylä VV. Cardiovascular Autonomic Reflexes in Brain Infarction. Stroke. 1994; 25:787-792

14. Dütsch M, Burger M, Dörfler C, Schwab S, Hilz MJ. Cardiovascular autonomic function in poststroke patients. Neurology 2007; 69 (24): 2249-2255.

15. Xiong L, Leung $\mathrm{H}$, Chen $\mathrm{XY}$, Han JH, Leung T, Soo $Y$ et al. Preliminary findings of the effects of autonomic dysfunction on functional outcome after acute ischemic stroke. Clinical Neurology and Neurosurgery 2012; 114: 316-320

16. Chien-Fu Chen, Chiou-Lian Lai, Hsiu-Fen Lin, Li-Min Liou, Ruey-Tay Lin. Reappraisal of heart rate variability in acute ischemic stroke. Kaohsiung Journal of Medical Sciences 2011; 27: 215.

17. Binici Z, Mouridsen MR, Køber L, Sajadieh A. Decreased night time heart rate variability is associated with increased stroke risk. Stroke. 2011; 42:3196-3201.
18. Tokgözoglu SL, Batur MK, Topçuoglu MA, Saribas O, Kes S, Oto A. Effects of stroke localization on cardiac autonomic balance and sudden death. Stroke. 1999 Jul; 30(7):1307-11. doi: 10.1161/01.str. 30.7.1307. PMID: 10390300.

19. Melillo P, Izzo R, Orrico A, Scala P, Attanasio M, Mirra $M$ et al. Automatic Prediction of Cardiovascular and Cerebrovascular Events Using Heart Rate Variability Analysis. PLOS ONE. 2015; 10(3): 0118504.

20. Xiong L, Leung HW, Chen XY, Leung WH, Soo OY, Wong KS. Autonomic dysfunction in different subtypes of post-acute ischemic stroke. Journal of the Neurological Sciences. 2014; 337:141-146.

21. Mikolich JR, Jacobs WC, Fletcher GF. Cardiac arrhythmias in patients with acute cerebrovascular accidents. JAMA. 1981; 246:1314 - 1317.

22. Mathew ST, Patel J, Joseph S. Atrial Fibrillation: mechanistic insights and treatment options. Euro J Int Med. 2009; 20:672-681.

23. Herweg B, Dalal p, Bibiana N, Schweitzer P. Power Spectral analysis of heart period variability of Preceding Sinus Rythm Before Initiation of Paroxysmal Atrial Fibrillation. Am J Cardiol. 1998;82:869-874.

24. Davenport RJ, Dennis MS, Wellwood I, Warlow CP. Complications after acute stroke. Stroke 1996; 27: 415- 420.

25. Lombardi F, Makikallio TH, Myerburg RJ, Huikuri HV. Sudden cardiac death: Role of heart rate variability to identify patients at risk. Cardiovasc Res. 2001; 50:210 -217.

26. Moroney JT, Bagiella E, Paik MC, Sacco RL, Desmond DW. Risk factors for early recurrence after ischaemic stroke: The role of stroke syndrome and subtype. Stroke. 1998; 29:2118-2124

27. Korpelainen JT, Sotaniemi AK, Makikallio A, Huikuri HV, Myllylä VV. Dynamic behavior of heart rate in ischemic stroke. Stroke 1999 May; 30(5):1008-13

28. Colivicchi F, Bassi A, Santini M, Caltagirone C. Prognostic Implications of Right-Sided Insular Damage, Cardiac Autonomic Derangement and Arrhythmias After Acute Ischemic Stroke. Stroke. 2005; 36:1710-1715

29. Bassi A, Colivicchi F, Santini M, Caltagirone C. Cardiac autonomic dysfunction and functional outcome after 
Swati Mishra et.al. Heart rate variability in patients of recurrent stroke as compared to patients of first-ever stroke.

ischaemic stroke. Eur J Neurol. 2007; 14(8):917-22

30. Ginsburg P, Bartur G, Peleg S, Vatine JJ, Katz-Leurer M. Reproducibility of Heart rate variability during rest, paced breathing and light-to -moderate intense exercise in patients one month after stroke. Eur Neurol. 2011;66(2):117-22

31. Orlandi G, Fanucchi S, Strata G, Pataleo L, LanducciPellegrini L, Prontera $\mathrm{C}$ et al. Transient autonomic nervous system dysfunction during hyperacute stroke. ActaNeurol Scand. 2000 Nov; 102(5): 317321
32. Böhm M, Cotton D, Foster L, Custodis F, Laufs U, Sacco R, Bath PM, Yusuf S, Diener HC. Impact of resting heart rate on mortality, disability and cognitive decline in patients after ischaemic stroke. Eur Heart $\mathbf{J}$ 2012; 33: 2804-12.

How to cite this article: Mishra S, Gupta S, Kapoor R et.al. Heart rate variability in patients of recurrent stroke as compared to patients of first-ever stroke. Int J Health Sci Res. 2022; 12(2):1-7. DOI: https://doi.org/10.52403/ijhsr. 20220201 